\title{
Comparison of post operative analgesia supraclavicular brachial plexus block in children 5 to 10 years of age
}

\author{
Bhargava $S^{1}$, Tamaskar $A^{2}$, Bhargava $S^{3}$, Bhargava $D^{4}$, Singh $M^{5}$ \\ ${ }^{1}$ Dr Sumit Bhargava, Associate Professor, ${ }^{2}$ Dr Aparna Tamaskar, Associate Professor, ${ }^{3}$ Dr Sudip Bhargava, DA DNB, \\ ${ }^{4}$ Dr Dipti Bhargava DA, ${ }^{5}$ Dr Manorama Singh, MD, DA, Professor and Head; all authors are affiliated with Department \\ of Anesthesiology and Critical Care, L. N. Medical College and J. K. Hospital, Kolar Road Bhopal, India.
}

Address for Correspondence: Dr Sumit Bhargava, Associate Professor of Anesthesiology and Critical Care, L. N. Medical College and J. K. Hospital, Kolar Road, Bhopal. Email: sumit_bhargava782000@yahoo.com

\begin{abstract}
Background: Regional anesthesia is a recommended technique for upper limb surgeries with better postoperative profile. However paediatric regional anaesthesia for upper limb surgeries was till now difficult due to various problems like moving child, inability to elicit parasthesia and likely injury to brachial plexeus. With the advent of nerve stimulators and ultrasound guided blocks, we can now overcome the above problems. We evaluated the effect of ultrasound guided bupivacaine for quality and duration of post op analgesia. Methodology: Sixty paediatric patients posted for elective and emergency upper limb surgeries were enrolled for a prospective, randomized, study. Patients were divided into two groups, the control group A and the study group B. In group A $(n=30)$ patients were given general anaesthesia for the surgery and at the end of it, conventional analgesics were given and In group B ( $=30)$, after GA, $10 \mathrm{ml}$ of $0.325 \%$ bupivacaine + normal saline were given ultrasound guided supraclavicular brachial plexus block. Quality and duration of post op analgesia and time to first rescue analgesia were recorded. Results. The onset times for pain was significantly shorter in A than B group $(p<0.05)$. The duration of analgesia (DOA) was significantly longer in B group than A group $(p<0.0001)$. Heart rate levels in group B were significantly lower 15 min after block $(p<0.001)$. SBP and DBP levels in B group were significantly lower than in A $(p<0.001)$. No major adverse effects were observed in either of the groups except for sedation 8 and respiratory depression in 6 patients of group A. Conclusion: Supraclavicular brachial plexus block significantly lengthens the onset time of pain and prolongs the duration of post op analgesia. Patients in group B had good quality analgesia with no adverse effects.
\end{abstract}

Keywords: Bupivacaine, Supraclavicular, Brachial plexus block.

\section{Introduction}

Upper limb surgeries are preferably done under regional anesthesia. Peripheral nerve blocks not only provide for intra operative anesthesia but also ensure analgesia in the post operative period without any systemic side effects. So far, all published reports on ultrasound guidance in regional anaesthesia have addressed its use in adults, although regional anaesthesia is being increasingly used in children, for whom most blocks are performed under sedation or anaesthesia. Thus, the use of ultrasound has important potential for paediatric anaesthesia. Ultrasonography

Manuscript received $24^{\text {th }}$ August 2016

Reviewed: $4^{\text {th }}$ September 2016

Author Corrected: $15^{\text {th }}$ September 2016

Accepted for Publication $27^{\text {th }}$ September 2016 has become an important tool for identifying nerves in the practice of regional anaesthesia. Our study group has demonstrated that approach to brachial plexus anaesthesia are facilitated with the use of ultrasound. The benefits of directly visualising the target nerves and monitoring the distribution of the local anaesthetic are potentially significant [1]. In addition, ultrasound monitoring allows repositioning of the needle in the event of maldistribution of the local anaesthetic and helps to avoid complications such as inadvertent intravascular or intrafascicular injection. The published data also suggest that ultrasound may improve the quality of nerve blockade [2]. In recent years, brachial plexus anaesthesia has become a valuable option in the 
post op management of upper limb surgery in children. This is particularly true in paediatric trauma surgery. The supraclavicular route, due to its safety and simplicity, has become the most commonly used approach for brachial plexus blockade in children [2]. However, a major drawback of this technique is that it not uncommonly produces poor analgesia when given blindly (depositing drug on $1^{\text {st }}$ rib) or by nerve stimulator [3]. A potential solution to this dilemma is to combine the brachial plexus anaesthesia with the comfort of directly visualising the plexus by ultrasonography, thereby obviating the need for nerve stimulation [1]. We therefore designed a prospective, randomised, blinded study in children undergoing surgical treatment of hand and forearm injuries to compare the quality and anaesthesia guided by ultrasound visualisation and the same block produced with the guidance of a nerve stimulator.

\section{Methodology}

After obtaining approval from the institutional ethical committee, patients were explained about the drug and after taking written consent were included in the study. Sixty paediatric patients of ASA physical status I and II, 5-10 years scheduled for forearm surgery under supraclavicular brachial plexus block were included in a prospective double blind randomized comparison.

Exclusion criteria included: Coagulopathy; cardiac, hepatic, renal or neurological disease; malformations of the upper limb; surgical contra-indications to regional anaesthesia.

All children were premedicated with midazolam $1 \mathrm{ml}$. After venous access was obtained and intravenous midazolam was given, and, propofol was given to produce GA. Routine monitoring comprised ECG, non-invasive blood pressure, capnography and pulse oximetry. The surgical procedures completed and thereafter brachial plexus anaesthesia given in one group and conventional analgesics to other group. The children's lungs were auscultated before and after brachial plexus anaesthesia to detect clinical signs of a pneumothorax. If there was clinical suspicion of a pneumothorax, a chest X-ray was taken. The puncture site was checked for haematoma or swelling caused by inadvertent puncture of major blood vessels. The puncture site was checked for potential infections on the first postoperative day.

Group B $(n=30)$ received $10 \mathrm{ml}$ of $0.325 \%$ bupivacaine with normal saline solution. Group A $(n=30)$ received GA and received conventional diclofenac suppository for analgesia. The anesthesiologist performing the block and observing the patient was blinded to the treatment group. Thereafter duration of post op analgesia, level of sedation were measured. Any need for rescue analgesia was noted. A visual analogue score (VAS) consisting of a 'smiley scale' ranging from 1 (no pain) to 5 (maximum pain) was recorded every 5 min to evaluate pain after the brachial plexus block in all children.

Statistical Analysis: After all parameters ; sex distribution and ASA grading were analyzed by chi-square test. Time for onset of pain was analyzed by student's unpaired 't-test'. Comparison of intraoperative complications like sedation and respiratory depression were analyzed by Fisher exact test.

The data was compiled and subjected to statistical analysis using Statistical Package for Social Sciences (SPSS), version 17. Demographic and hemodynamic data were subjected to Student's 't-test' and for statistical analysis of onset time. $p$ value was considered as significant as shown below $\mathrm{p}>0.05$ not significant, $\mathrm{p}<0.05$ significant, $\mathrm{p}<0.0001$ highly significant.

\section{Observation Tables}

Table-1: Comparison of duration of analgesia and level of sedation.

\begin{tabular}{|c|c|c|c|}
\hline & Group A & Group B & p-value \\
\hline Onset of pain(Min) & $172.4 \pm 41.26$ & $318.6 \pm 32.46$ & $<0.001$ \\
\hline Resque Analgesia (Min) & $246 \pm 20.31$ & $468.56 \pm 40.7$ & $<0.001$ \\
\hline Sedation Score (1-4) & 2.8 & 1 & \\
\hline
\end{tabular}


Table-2: Comparison of pulse, Mean Systolic BP and mean diastolic BP between both groups.

\begin{tabular}{|c|c|c|c|c|c|c|c|c|c|}
\hline & \multicolumn{3}{|c|}{ Pulse } & \multicolumn{3}{c|}{ Mean Systolic BP } & \multicolumn{3}{c|}{ Mean diastolic BP } \\
\hline & Group A & Group B & $\begin{array}{c}\text { p- } \\
\text { value }\end{array}$ & Group A & Group B & p- & $\begin{array}{c}\text { Group } \\
\text { Group } \\
\text { value }\end{array}$ & $\begin{array}{c}\text { p- } \\
\text { B } \\
\text { value }\end{array}$ \\
\hline 0 min & $120 \pm 3.6$ & $121 \pm 2.8$ & $>0.05$ & $124.46 \pm 2.42$ & $110.3 \pm 6.29$ & $>0.05$ & $60 \pm 4.2$ & $60 \pm 3.6$ & $>0.05$ \\
\hline 1 hour & $126 \pm 3.2$ & $110 \pm 3.6$ & $<0.001$ & $122.76 \pm 6.58$ & $102.46 \pm 6.19$ & $<0.001$ & $62 \pm 4.1$ & $62 \pm 3.4$ & $<0.001$ \\
\hline 2 hours & $123 \pm 3.6$ & $102 \pm 3.6$ & $<0.001$ & $116.43 \pm 4.65$ & $102.16 \pm 2.41$ & $<0.001$ & $68 \pm 3.6$ & $60 \pm 3.8$ & $<0.001$ \\
\hline 3 hours & $122 \pm 3.6$ & $108 \pm 2.2$ & $<0.001$ & $123.56 \pm 3.12$ & $102.86 \pm 38.30$ & $<0.001$ & $66 \pm 3.5$ & $58 \pm 4.1$ & $<0.001$ \\
\hline 4 hours & $124 \pm 3.6$ & $104 \pm 4.2$ & $<0.001$ & $126.4 \pm 2.41$ & $102.72 \pm 7.70$ & $<0.001$ & $70 \pm 3.2$ & $61 \pm 2.4$ & $<0.001$ \\
\hline 5 hours & $124 \pm 3.6$ & $104 \pm 2.6$ & $<0.001$ & $118.3 \pm 6.36$ & $104.9 \pm 6.27$ & $<0.001$ & $72 \pm 1.8$ & $60 \pm 2.8$ & $<0.001$ \\
\hline 6 hours & $128 \pm 2.6$ & $106 \pm 4.6$ & $<0.001$ & $122.43 \pm 4.65$ & $106.16 \pm 2.42$ & $<0.001$ & $74 \pm 2.4$ & $61 \pm 3.2$ & $<0.001$ \\
\hline
\end{tabular}

Table-3: Postoperative Complications.

\begin{tabular}{|c|c|c|c|c|}
\hline S. No. & Complication & GROUP A & GROUP B & P value \\
\hline 1 & Sedation & 8 & Nil & $<0.05$ \\
\hline 2 & Respiratory depression & 6 & Nil & $<0.05$ \\
\hline 3 & Nausea and vomiting & 4 & Nil & $<0.05$ \\
\hline
\end{tabular}

\section{Observations}

The demographic data and surgical characteristics were comparable in both groups. Onset time was shorter while duration of sensory and motor blockade was longer in BD than B group and the difference was statistically significant ( $p<0.05$ ). Table 1 depicts the mean onset time for pain in group A and group B, respectively. The mean duration of analgesia (DOA) for group B was $468.56 \pm 41.7 \mathrm{~min}$, it was $246 \pm 40.31 \mathrm{~min}$ for group A (Table 1). DOA was significantly longer in group B than group A $(p<0.001)$. HR, SBP, and DBP in group B at 1,2, 3, 4,5 Hours were significantly lower than in group B $(p<0.001)$ (Table 3). In fact, when the percentage changes in the HR, SBP, and DBP were compared, they were highly significant $(p<0.001)$.

\section{Discussion}

Upper limb surgeries are preferably done under regional anesthesia. Peripheral nerve blocks not only provide for intra operative anesthesia but also ensure analgesia in the post operative period without any systemic side effects. So far, all published reports on ultrasound guidance in regional anaesthesia have addressed its use in adults, although regional anaesthesia is being increasingly used in children, for whom most blocks are performed under sedation or anaesthesia. Thus, the use of ultrasound has important potential for paediatric anaesthesia.

Dalens B et al evaluated the potential of regional anesthesia in children. This prospective study, based on a large and representative series of pediatric anesthetics, establishes the safety of regional anesthesia in children of all ages. It provides new insights on the practice of regional blocks and reveals that complications are rare and minor as they occur most often in the operating room and are readily managed by experienced anesthesiologists with resuscitative equipment at hand. The extremely low incidence of complications (zero in this study) after peripheral nerve blocks should encourage pediatric anesthesiologists to use them more often when they are appropriate, in the place of a central block [1].

Ecoffey C, Lacroix F, Giaufré E, Orliaguet G et al studied the various aspects of epidemiology and morbidity of regional anesthesia in children They concluded that in children aged $\leq 3$ years, the percentage of central blocks was similar to the peripheral ones (45\% vs 55), while in older children, peripheral blocks were more than four times used than central ones. Complications (41 involving 40 patients) were rare and usually minor. They did not result in any sequelae. The 
study revealed an overall rate of complication of $0.12 \%$; CI 95\% [0.09-0.17], significantly six times higher for central than for peripheral blocks. As a result of the low rate of complications, RA techniques have a good safety profile and can be used to provide postoperative analgesia. In addition, the results should encourage anesthesiologists to continue to use peripheral instead of central (including caudal) blocks as often as possible when appropriate [2]. They did a follow-up one-year prospective survey of the French-Language Society of Paediatric Anaesthesiologists (ADARPEF).

Lönnqvist PA, Morton NS et al did their research on postoperative analgesia in infants and children [3]. Dadure C, Capdevila X et al did work on continuous peripheral nerve blocks in children. They studied new techniques, such as transcutaneous stimulation or ultrasound guidance, appear to facilitate nerve and plexus identification in paediatric patients. Nevertheless, continuous peripheral nerve block may mask compartment syndrome in certain surgical procedure or trauma. Finally, ropivacaine appears to be the best local anaesthetic for continuous peripheral nerve blocks in children, requiring low flow rate with low concentration of the local anaesthetic [4].

Our's is the study describing the use of ultrasound guidance in paediatric regional anaesthesia for post op pain management. Its results demonstrate that ultrasound visualisation of the brachial plexus is highly effective in children. These observations are in keeping with our previous studies of regional anaesthesia in the upper and lower limbs of adults, and result from the fact that ultrasound visualisation optimises the proximity of the placement of the local anaesthetic to the targeted nerve structures. Kapral S, et al also studied the same and concluded that ultrasonographic guidance improves the success rate of interscalene brachial plexus blockade [5]. Similar study was done by Marhofer P, Sitzwohl C, Greher M et al who used ultrasound guidance for infraclavicular brachial plexus anaesthesia in children [6].

Various authors till now have done various researches on paediatric brachial plexeus blocks Inberg $\mathrm{P}$ et al gave blocks for microvascular surgery in children. Jose Maria B et al did a a preliminary study on vertical infraclavicular brachial plexus block in children [7-10]. Cheng GL et al used blocks for digital replantation in children [11]. Eriksson E. gave axillary brachial plexus anaesthesia in children Pande $\mathrm{R}$ et al did an analysis of 200 cases on supraclavicular brachial plexus block as a sole anaesthetic technique in children [12,13] Cramer $\mathrm{KE}$ et al studied the reduction of forearm fractures in children using axillary block anesthesia. Fleischmann E et al did their work on brachial plexus anaesthesia in children via lateral infraclavicular vs axillary approach $[14,15]$.

The acute pain caused by brachial plexus puncture under nerve stimulator guidance due to muscle contractions is totally eliminated by ultrasound guidance, thus decreasing the pain felt at the time of block performance to a more comfortable level. Similar observations were made by study done by De Jose et al in which they compared ultrasound-guided supraclavicular vs infraclavicular brachial plexus blocks in children [16].

Although we have not formally investigated patient and parental satisfaction, our experience with > 90 ultrasound-guided brachial plexus blocks in children leaves us in no doubt that the technique described will make all parties involved feel better about the entire procedure.

Hicks CL et al made the Faces Pain Scale- Revised; a common metric in pediatric pain measurement exists. Van Dijk et al evaluated the reliability and validity of the COMFORT scale as a postoperative pain instrument in 0 to 3-year-old infants. Wong DL, Baker CM. studied pain in children by comparison of assessment scales. Compared to nerve stimulator guidance, ultrasound visualisation offers shorter sensory onset times, thus decreasing the period in which the children feel pain $[17,18,19]$.

Furthermore, more nerves are blocked more effectively with ultrasound guidance than with the nerve stimulator technique during the onset phase of the block. The longer duration of sensory blockade improves postoperative analgesia without increasing the incidence of side effects - a benefit unattainable with systemic analgesic drugs. The reason for the faster onset time and the longer duration of sensory block with ultrasound guidance is probably a more accurately targeted delivery of the local anaesthetic to the brachial plexus. Although supraclavicular plexus anaesthesia has not been reported to be associated with complications, e.g. pleural puncture or inadvertent intravascular injection of the local anaesthetic, the safety implications of ultrasound visualisation are evident $[15,16]$. 
Often-cited arguments against the use of ultrasound in regional anaesthesia are the associated costs and the space requirements for storage and use of the ultrasound equipment. Ultrasound systems have been decreased in size to the dimensions of a laptop computer in the past few years, while the cost of these miniaturised systems has decreased to one-tenth the cost of conventional ultrasound systems. These facts will hopefully weaken the arguments relating to cost and space requirements, and enhance the use of ultrasound guidance, not only for infraclavicular brachial plexus anaesthesia in children, but also for other regional anaesthesia techniques in all age groups for which it has been shown to be effective.

In the recent edition of 'Current Opinion in Anesthesiology' accor to Klaastad et al who studied Brachial plexus block with or without ultrasound guidance, they found both quality and duration improves in ultrasound guided blocks. This was in accordance to study done by Rochette A et al who did a review of pediatric regional anesthesia practice during a 17-year period in a single institution and found use of ultrasound better than other methods De Negri et al did their study on new local anesthetics for pediatric anesthesia [20,21,22]. This new technique requires specialist training. Nerve blocks no longer require anatomical landmarks, e.g. bones or blood vessels, or complex calculations, but they do demand that anaesthetists adopt a new perspective. We hope that this study contributes to the acceleration of this 'paradigm shift' in regional anaesthesia.

During initial attempts at ultrasound-guided plexus anaesthesia, the orientation of the tip of the needle in relation to the ultrasound picture feels unfamiliar. However, in our experience, it takes only 15-20 supervised attempts to obtain successful blocks.

\section{Conclusion}

In conclusion, ultrasound guidance allows direct visualisation of brachial plexus in paediatric anaesthesia. Due to the absence of muscle contractions, this method is less painful for the children than nerve stimulator guidance. Moreover, ultrasound guidance decreases sensory and motor onset times, and prolongs the duration of sensory blockade. Therefore, ultrasound visualisation offers advantages over nerve stimulation for the performance of infraclavicular brachial plexus anaesthesia in children and will hopefully become a standard technique for plexus anaesthesia in children.
Significant difference was seen in postoperative diclofenac and opioid requirement.

Funding: Nil, Conflict of interest: None initiated, Permission from IRB: Yes

\section{References}

1. Dalens B. Regional anesthesia in children. Anesth Analg. 1989 May;68(5):654-72.

2. Ecoffey C, Lacroix F, Giaufré E, Orliaguet G, Courrèges P. Epidemiology and morbidity of regional anesthesia in children: a follow-up one-year prospective survey of the French-Language Society of Paediatric Anaesthesiologists (ADARPEF). Pediatric Anesthesia. 2010 Dec 1;20(12):1061-9.

3. Lönnqvist PA, Morton NS. Postoperative analgesia in infants and children. Br J Anaesth. 2005 Jul;95(1): 5968. Epub 2005 Jan 21.

4. Dadure C, Capdevila X. Continuous peripheral nerve blocks in children. Best Practice \& Research Clinical Anaesthesiology. 2005 Jun 30;19(2):309-21.

5. Kapral S, Greher M, Huber G, Willschke H, Kettner S, Kdolsky R, Marhofer P. Ultrasonographic guidance improves the success rate of interscalene brachial plexus blockade.Regional anesthesia and pain medicine. 2008 Jun 30;33(3):253-8.

6. Marhofer P, Sitzwohl C, Greher M, Kapral S. Ultrasound guidance for infraclavicular brachial plexus anaesthesia in children. Anaesthesia. 2004 Jul; 59 (7):642-6.

7. Inberg P, Kassila M, Vilkki S, Tarkkila P, Neuvonen P. Anaesthesia for microvascular surgery in children. A combination of general anaesthesia and axillary plexus block. Acta Anaesthesiol Scand. 1995 May; 39 (4): 518-22.

8. Jose Maria B, Tielens LK. Vertical infraclavicular brachial plexus block in children: a preliminary study. Pediatric Anesthesia. 2004 Nov 1;14(11):931-5.

9. Tobias JD. Brachial plexus anaesthesia in children. Paediatr Anaesth. 2001 May;11(3):265-75.

10. Ivani G, Mosseti V. Pediatric regional anesthesia. Minerva Anestesiol. 2009 Oct;75(10):577-83. 
11. Cheng GL, Pan DD, Yang ZX, Fang GR, Gong XS. Digital replantation in children. Ann Plast Surg. 1985 Oct; 15(4):325-31.

12. Eriksson E. Axillary brachial plexus anaesthesia in children with Citanest. Acta Anaesthesiol Scand Suppl. 1965; 16:291-6.

13. Pande R, Pande M, Bhadani U, Pandey CK, Bhattacharya A. Supraclavicular brachial plexus block as a sole anaesthetic technique in children: an analysis of 200 cases. Anaesthesia. 2000 Aug 17;55(8):798802 .

14. Cramer KE, Glasson S, Mencio G, Green NE. Reduction of forearm fractures in children using axillary block anesthesia. Journal of orthopaedic trauma. 1995 Oct 1;9(5):407-10.

15. Fleischmann E, Marhofer P, Greher M, Waltl B, Sitzwohl C, Kapral S. Brachial plexus anaesthesia in children: lateral infraclavicular vs axillary approach. Pediatric Anesthesia. 2003 Feb 1;13(2):103-8.

16. De Jose Maria B, BanUS E, Navarro Egea M, Serrano S, PerellO M, Mabrok M. Ultrasound-guided supraclavicular vs infraclavicular brachial plexus blocks in children. Pediatric Anesthesia. 2008 Sep 1;18(9): 838-44.
17. Hicks CL, von Baeyer CL, Spafford PA, van Korlaar I, Goodenough B. The Faces Pain ScaleRevisedtoward a common metric in pediatric pain measurement. Pain. 2001 Aug 31;93(2):173-83.

18. van Dijk M, de Boer JB, Koot HM, Tibboel D, Passchier J, Duivenvoorden HJ. The reliability and validity of the COMFORT scale as a postoperative pain instrument in 0 to 3-year-old infants. Pain. 2000 Feb; 84 (2-3):367-77.

19. Wong DL, Baker CM. Pain in children: comparison of assessment scales. Pediatr Nurs. 1988 Jan-Feb; 14(1):9-17.

20. Klaastad O, Sauter AR, Dodgson MS. Brachial plexus block with or without ultrasound guidance. Curr Opin Anaesthesiol. 2009 Oct; 22(5): 655-60. doi: 10. 1097/ ACO.0b013e32832eb7d3.

21. Rochette A, Dadure C, Raux O, Troncin R, MAILHEé PH, Capdevila X. A review of pediatric regional anesthesia practice during a 17 -year period in a single institution. Pediatric Anesthesia. 2007 Sep 1;17 (9):874-80.

22. De Negri P, Ivani G, Tirri T, Del Piano AC. New local anesthetics for pediatric anesthesia. Curr Opin Anaesthesiol. 2005 Jun;18(3):289-92.

\section{How to cite this article?}

Bhargava S,Tamaskar A, Bhargava S, Bhargava D, Singh M. Comparison of post operative analgesia supraclavicular brachial plexus block in children 5 to 10 years of age. Int J Med Res Rev 2016;4(9):1681-1686.doi:10.17511/ijmrr. 2016.i09.28. 